University of Nebraska - Lincoln

DigitalCommons@University of Nebraska - Lincoln

Robert G. Fuller Publications and Presentations Research Papers in Physics and Astronomy

March 1968

\title{
ELECTRICAL CONDUCTIVITY OF POTASSIUM CHLORIDE
}

Robert Fuller

rfuller@neb.rr.com

Michael H. Reilly

U. S. Naval Research Laboratory, Washington, D. C.

Charles L. Marquardt

U. S. Naval Research Laboratory, Washington, D. C.

John C. Wells

U. S. Naval Research Laboratory, Washington, D. C.

Follow this and additional works at: https://digitalcommons.unl.edu/physicsfuller

Part of the Physics Commons

Fuller, Robert; Reilly, Michael H.; Marquardt, Charles L.; and Wells, John C., "ELECTRICAL CONDUCTIVITY OF POTASSIUM CHLORIDE" (1968). Robert G. Fuller Publications and Presentations. 13.

https://digitalcommons.unl.edu/physicsfuller/13

This Article is brought to you for free and open access by the Research Papers in Physics and Astronomy at DigitalCommons@University of Nebraska - Lincoln. It has been accepted for inclusion in Robert G. Fuller Publications and Presentations by an authorized administrator of DigitalCommons@University of Nebraska - Lincoln. 
We are presently studying the same phenomenon in the Hall-effect geometry (previously referred to as case $A$ ), but the signal is quite small $\left(10^{-11} \mathrm{~V} \mathrm{~cm}^{2} / \mathrm{A}\right)$ and cons equently difficult to detect.

The authors wish to express their gratitude to Professor P. Nozières who suggested this experiment. We also thank Dr. E. Fawcett for many stimulating discussions and his assistance in preparing the manuscript.

*Work supported in part by Direction des Recherches et Moyens d'Essais.

$\dagger$ Laboratory associated with the Centre National de la Recherche Scientifique.

${ }^{1} \mathrm{~F}$. London, Superfluids (John Wiley \& Sons, Inc., New York, 1950), Vol. 1, pp. 55, §8.

${ }^{2}$ H. Lewis, Phys. Rev. $\underline{92}, 1149$ (1953), and $\underline{100,} 641$ (1955).

${ }^{3}$ R. Jaggi and R. Sommerhalder, Helv. Phys. Acta 32, 167 (1959).

${ }^{4}$ D. Shoenberg, Superconductivity (Cambridge University Press, New York, 1952), p. 49.

${ }^{5}$ W. A. Zisman, Rev. Sci. Instr. $\underline{3}, 367$ (1932); and Ralph E. Simon, Phys. Rev. 116, 613 (1959).

\title{
ELECTRICAL CONDUCTIVITY OF POTASSIUM CHLORIDE
}

\author{
Robert G. Fuller, Michael H. Reilly,* Charles L. Marquardt, and John C. Wells, Jr. $\dagger$ \\ U. S. Naval Research Laboratory, Washington, D. C.
}

(Received 30 January 1968)

\begin{abstract}
The electrical conductivity of potassium chloride is discussed within the framework of a four-defect model of the crystal. The four defects are mobile anion and cation vacancies and immobile divalent cation impurities and divalent cation impurity-cation vacancy complexes. The Teltow formulation of the four-defect model fails to describe precisely the measured electrical conductivity of $\mathrm{KCl}$ over the entire intrinsic and extrinsic range.
\end{abstract}

The electrical conductivity of alkali-halide crystals has usually been discussed in terms of a four-defect model of an ionic crystal, the four defects being anion vacancies, cation vacancies, divalent impurity cations, and divalent cation impurity - cation vacancy complexes. In the Teltow formulation ${ }^{1}$ of the four-defect model the defects are treated as noninteracting particles, the divalent cation impurities and cation vacancies are considered as complexes only when they are on nearest-neighbor lattice sites, and the mobility of the ions is given by the product of a jump-attempt frequency $(\nu)$ and a Boltzmann factor. It has been customary in the analysis of conductivity data to extract values for the various parameters, assumed to be temperature independent in the Teltow formulation, i.e., the entropy $(s)$ and enthalpy $(h)$ of Schottky-defect formation, the entropies $\left(\Delta s_{ \pm}\right)$and enthalpies $\left(\Delta h_{ \pm}\right)$of vacancy motion, and the binding energy of the complexes. It is our intent to show the limitations of the Teltow formulas for $\mathrm{KCl}$.

In the intrinsic region where the effect of the impurity content is negligible, the Teltow expression for the conductivity reduces to the sum of two exponentials,

$$
\sigma T=\frac{N a^{2} e^{2} \nu}{k}\left[\exp \left(S_{+}-\frac{W_{+}}{k T}\right)+\exp \left(S_{-}-\frac{W_{-}}{k T}\right)\right],
$$

where $N$ is the number of cations per unit volume, $a$ is the lattice parameter, $e$ is the electronic charge, $S_{ \pm}=\left(\frac{1}{2} s+\Delta s_{ \pm}\right) / k$ and $W_{ \pm}=\frac{1}{2} h+\Delta h_{ \pm}$. A test of the Teltow formulation is to see if a sum of two exponentials will describe the intrinsic conductivity and gives results consistent with analyses of conductivity over a wider temperature range which includes the extrinsic region.

The electrical conductivity of "pure" Harshaw $\mathrm{KCl}$ crystals has been measured from 480 to $750^{\circ} \mathrm{C}$ using standard ac bridge techniques at $1 \mathrm{kHz}$ and a furnace design which permits the taking of measurements every $3^{\circ}$ or so. A higher density of data points than reported for other experiments of this type has thus been obtained. In Fig. 1 the data from our measurements of the conductivity of Harshaw $\mathrm{KCl}$ are shown by open circles and the data from the measurements of the conductivity of zone-refined $\mathrm{KCl}$ (data of Ref. 2, run No. 9) are shown by solid squares. The precision of our measurements is estimated to be $\pm 1 \%$ for the conductivity and $\pm 0.5^{\circ} \mathrm{C}$ for the temperature. The least-squares computer fit of Eq. (1) with the 59 experimental data points for $T>560^{\circ} \mathrm{C}$ is shown by the solid line in Fig. 1.

Two difficulties are encountered in the use of Eq. (1) to analyze conductivity data. One is the determination of the temperature at which 


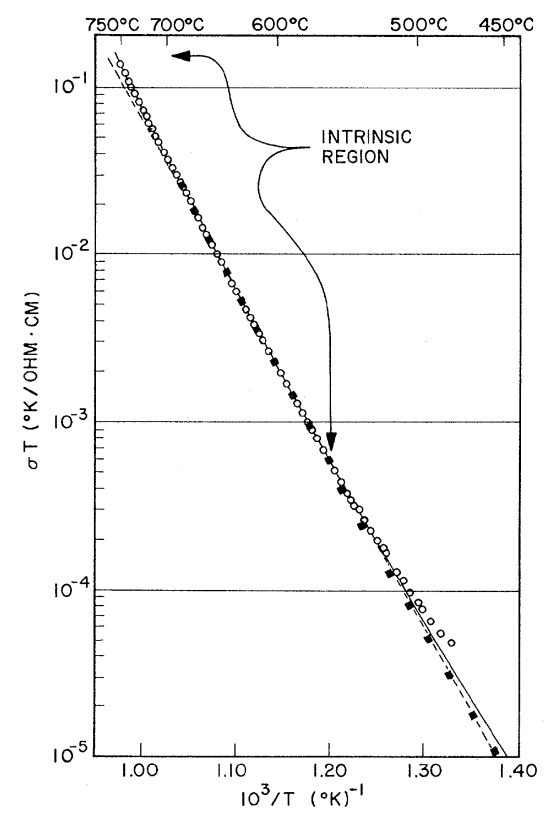

FIG. 1. The electrical conductivity of $\mathrm{KCl}$ as a function of temperature. Open circles, experimental data for Harshaw $\mathrm{KCl}$; solid squares, experimental data for zone-refined $\mathrm{KCl}$ (Ref. 2, run No. 9); solid line, least-squares fit of Eq. (1) with the intrinsic region $\left(T>560^{\circ} \mathrm{C}\right)$; dashed line, results from Beaumont and Jacobs' (Ref. 2) analysis of intrinsic and extrinsic conductivity of $\mathrm{KCl}$.

the intrinsic region begins and the other is the verification of the uniqueness of the parameters obtained by the computer fit.

Two $\mathrm{KCl}$ crystals containing small but different amounts of aliovalent cation impurities have equal values of electrical conductivity only in the intrinsic region. The data for the Harshaw $\mathrm{KCl}$ and the zone-refined $\mathrm{KCl}$ are equal with a mean deviation of $1.2 \%$ for $T>560^{\circ} \mathrm{C}$. Therefore, the temperature range above $560^{\circ} \mathrm{C}$ can safely be designated as the intrinsic region (Fig. 1).

The reliability of our computer program was determined by manufacturing data for a sum of exponentials with known parameter values and affixing computer-generated random errors, so that the least-squares fit to Eq. (1) with the test data and with the experimental data gave equal $\mathrm{rms}$ deviations. The analysis of ten sets of 59 test data points permitted us to verify the uniqueness of our results and to estimate the precisions of $S_{ \pm}$and $W_{ \pm}$. The corrected values and related uncertainties of these four parameters are given in row 1, Table I, along with the $\mathrm{rms}$ fractional deviation between Eq. (1) and the experimental data for $T>560^{\circ} \mathrm{C}$.

Beaumont and Jacobs ${ }^{2}$ have measured the electrical conductivity of several undoped $\mathrm{KCl}$ single crystals (of which the squares of Fig. 1 are one sample) for $690>T>370^{\circ} \mathrm{C}$. For their analysis they used the Teltow equations, which required a seven-parameter least-squares computer fit. Their values for the parameters of Eq. (1) are shown in row 2, Table I. Despite the conclusion from the Teltow model that the conductivity should reduce to a four-parameter description, Eq. (1), in the intrinsic region, the following facts may be observed:

(1) The analysis of the intrinsic and extrinsic regions together for undoped $\mathrm{KCl}$ gives entropy and enthalpy values significantly different from those obtained in the analysis of the intrinsic region alone.

(2) The computed values for conductivity resulting from the analysis of the intrinsic and extrinsic regions together are below the experimental data for all temperatures above $665^{\circ} \mathrm{C}$ and are low by more than $10 \%$ above $730^{\circ} \mathrm{C}$.

Recent results for the conductivity of nearly pure $\mathrm{KBr}$ reported by Dawson and Barr ${ }^{3}$ are similar to these results for $\mathrm{KCl}$. Dawson and Barr analyzed their conductivity data over a wide temperature range $\left(T>290^{\circ} \mathrm{C}\right)$ and over the intrinsic region $\left(T>560^{\circ} \mathrm{C}\right)$ alone. They

Table I. Entropies and enthalpies for electrical conductivity in potassium chloride. The rms deviation was computed using Eq. (1) and the experimental data for $T>560^{\circ} \mathrm{C}$. The value used for the jump-attempt frequency $\nu$ was $4.276 \times 10^{12} \mathrm{sec}^{-1}$.

\begin{tabular}{|c|c|c|c|c|c|}
\hline & $S_{-}$ & $\begin{array}{l}W \\
(\mathrm{eV})\end{array}$ & $S_{+}$ & $\begin{array}{l}W_{+} \\
(\mathrm{eV})\end{array}$ & $\begin{array}{c}\text { Rms deviation } \\
(\%)\end{array}$ \\
\hline $\begin{array}{l}\text { Intrinsic conductivity } \\
\text { (this work) }\end{array}$ & $11.6 \pm 0.3$ & $2.36 \pm 0.03$ & $2.1 \pm 0.6$ & $1.66 \pm 0.04$ & 1.3 \\
\hline $\begin{array}{l}\text { Intrinsic and } \\
\text { extrinsic conductivity }\end{array}$ & 9.0 & 2.17 & 4.5 & 1.84 & 6.2 \\
\hline
\end{tabular}

$\mathrm{a}_{\text {Ref. } 2 \text {. }}$ 
reported that, although the analysis for the wide temperature range gives results in agreement with their analysis of diffusion data, the analysis of the intrinsic-extrinsic regions gives entropy and enthalpy values significantly different from those obtained by their analysis of the intrinsic region only. The computed values of conductivity resulting from their intrinsic-extrinsic analysis are below the values computed from the intrinsic analysis for all temperature above $589^{\circ} \mathrm{C}$, are more than $10 \%$ low for $T>660^{\circ} \mathrm{C}$, and fall $20 \%$ low near $700^{\circ} \mathrm{C}$.

In summary, our analysis shows that a reliable least-squares fit of Eq. (1) to the intrinsic conductivity of $\mathrm{KCl}$ can be obtained and that the parameters of the fit are uniquely determined within the uncertainties given in row 1, Table I. On the other hand, results of an analysis using the Teltow equations for both the intrinsic and the extrinsic regions of undoped $\mathrm{KCl}$ crystals do not agree with the intrinsic data. Furthermore, these analyses give enthalpies that differ by about $10 \%$ and entropies that differ by as much as a factor of 2 or more.

Two possibilities for bringing the conductivity theory into agreement with experiment seem to exist. One possibility is the existence of other charge carriers, such as trivacancy complexes, Frenkel defects, or electrons (or holes) thermally liberated from impurity traps. One or more of these carriers, associated with higher activation energies, might appear in the intrinsic region in sufficient concentrations to account for the discrepancy. On the other hand, it seems likely that the Teltow formulation oversimplifies the four-defect model. The addition of long-range Coulomb interactions to the Teltow equations has been made by Lidiard ${ }^{4}$ using the Debye-Hückel theory for electrolytic solutions. However, we have found in preliminary calculations that the discrepancy between theory and experiment is only slightly lessened by the use of the Lidiard formulation of conductivity theory. The vacancy concentration in the intrinsic may well be too large for the Debye-Hückel approximations to be valid. ${ }^{5-7}$ For example, the ratio of $e^{2} K /$ $\epsilon k T$ is assumed to be much less than 1 in the Debye-Hückel treatment, where $K$ and $\epsilon$ refer to the Debye-Hückel screening constant and the static dielectric constant, respectively. ${ }^{5}$ In fact, the ratio increases with temperature in the intrinsic region of $\mathrm{KCl}$ from about 0.3 to 1.0. Defect interactions may therefore be underestimated in the Lidiard formulation. Moreover, a variation with temperature of the free energy of motion may be an important effect which would become apparent in a more careful treatment of the influence of the lattice vibrations. In any event, one is forced to conclude that no consistent set of temperatureindependent parameters in the Teltow equations can adequately describe both the intrinsic and extrinsic regions of electrical conductivity of $\mathrm{KCl}$.

* Postdoctoral Resident Research Associate.

$\dagger$ Present address: Physics Department, Johns Hopkins University, Baltimore, Md。

${ }^{1} \mathrm{~J}$. Teltow, Ann. Physik $\underline{5}, 71$ (1949).

${ }^{2}$ J. H. Beaumont and P. W. Jacobs, J. Chem. Phys. $45,1496(1966)$.

${ }^{3}$ D. K. Dawson and L. W. Barr, Phys. Rev. Letters 19, 844 (1967).

${ }^{4}$ A. B. Lidiard, Phys. Rev. 94, 29 (1954)。

${ }^{5}$ R. H. Fowler and E. A. Guggenheim, Statistical Thermodynamics (Cambridge University Press, Cambridge, England, 1939), Chap. 9.

${ }^{6}$ A. R. Allnatt and M. H. Cohen, J. Chem. Phys. 40, 1871 (1964); E. Koch and C. Wagner, Z. Physik Chem. 38,295 (1937).

${ }^{7}$ A. R. Allnatt and P. C. Hoines, J. Chem. Phys. $\underline{46}$, 1154 (1967). 